\title{
Pathogen inactivation method using ultraviolet C light
}

\author{
Elżbieta Lachert@ \\ Institute of Hematology and Transfusion Medicine, Warsaw
}

\begin{abstract}
Summary
Since the end of the 1990s pathogen inactivation methods were being gradually implemented into routine work of blood transfusion establishments in many countries with regard to blood components dedicated for clinical use. The developed pathogen inactivation methods were either based on chemical compounds eg. the solvent detergent (SD) inactivation method or on photochemical and photodynamic reactions eg. inactivation methods with methylene blue, amotosalen hydrochloride and riboflavin. Blood components inactivated with any of the above mentioned methods still had traces of chemical compounds although removal steps were added (an exception here is the method with riboflavin). Attempts were therefore undertaken to develop an inactivation method based not on chemical compounds but on specific wavelength irradiation. An example of such inactivation method solely based on properties of short-wave UVC-light (UVC) with no photosensitizing chemicals is the Theraflex UV-Platelets system dedicated to platelet concentrates (PCs). The system uses $254 \mathrm{~nm}$ wavelength irradiation which is not absorbed by proteins so conventional toxicity tests are not required. The method is effective for clinically significant both $G(+)$ and $G(-)$ bacteria as well as viruses and protozoa. Clinical trials demonstrated reduced recovery of UVC-irradiated platelets and shorter survival time in the recipient's organism.
\end{abstract}

\section{Key words: pathogen inactivation, UVC light, platelet concentrate}

J. Transf. Med. 2019; 12: 83-87

\section{Introduction}

Since late 1990s pathogen inactivation of blood components dedicated for transfusion was implemented into routine work of blood establishments in many countries. The inactivation methods first drew on the experience of pathogen inactivation in plasma fractionation processes. The solvent/detergent (SD) inactivation method in use since 1985 was modified and applied since 1991 for inactivation of plasma for clinical use. At the same time, an inactivation method with methylene blue was developed to reduce the risk of pathogen transmission through transfused plasma [1, 2].
The first decade of the 21 st century witnessed both the development of new methods of pathogen inactivation as well as improvement of the methods already in use. Macopharma for instance, modified the methylene blue method of plasma inactivation and developed a system called Theraflex MBPlasma (CE- marked 2000).

Amotosalen hydrochloride was used in the Intercept system developed for pathogen inactivation, first in PCs (CE marked 2002) and then in plasma (CE marked 2006). The Mirasol ${ }^{\circledR} \mathrm{PRT}$ system used riboflavin for pathogen inactivation in both PCs (CE marked 2007) and plasma (CE marked 2008). The above-mentioned systems are in routine use for pathogen inactivation in both

Correspondence address: Elżbieta Lachert, Institute of Hematology and Transfusion Medicine, 14 Indiry Gandhi St., 02-776 Warsaw 
Table 1. Pathogen inactivation methods in blood components

\begin{tabular}{|c|c|c|c|c|}
\hline System & $\begin{array}{l}\text { Theraflex } \\
\text { MB Plasma }\end{array}$ & Intercept & Mirasol PRT & $\begin{array}{l}\text { Theraflex } \\
\text { UV-Platelets }\end{array}$ \\
\hline Blood component & Plasma & Plasma, PC & Plasma, PC & PC, plasma? \\
\hline CE & 2000 & PC: 2002 & PC: 2007 & PC: 2009 \\
\hline (yr) & & plasma: 2006 & plasma: 2008 & \\
\hline Photosensitizer & Methylene blue & $\begin{array}{l}\text { Amotosalen } \\
\text { hydrochloride }\end{array}$ & Riboflavin & No photosensitizer \\
\hline Photoproducts & Azure $A, B, C$; thionine & Dimers S-59 & $\begin{array}{l}\text { Lumichrome, lumiflavin } \\
\text { and their derivatives }\end{array}$ & No photoproduct \\
\hline \multirow{2}{*}{$\begin{array}{l}\text { Conditions } \\
\text { of inactivation }\end{array}$} & Visible light & UVA & UV & UVC \\
\hline & $180 \mathrm{~J} / \mathrm{cm}^{2}$ & $3 \mathrm{~J} / \mathrm{cm}^{2}$ & $6,24 \mathrm{~J} / \mathrm{cm}^{2}$ & $0,2 \mathrm{~J} / \mathrm{cm}^{2}$ \\
\hline Additional steps & Plasmaflex, Bluflex & CAD & NA & NA \\
\hline
\end{tabular}

plasma and PCs. However, work is still in progress on the implementation of pathogen inactivation methods in whole blood (WB) and red blood cells as well as on development of methods that do not rely on photosensitizing compounds [3-5].

An example of a method developed for pathogen inactivation in PCs which is solely based on UVC and does not include the addition of a photosensitive compound is the Theraflex UV-Platelets system. Pathogen inactivation methods for plasma and $\mathrm{PCs}$ differ with regard to irradiation wavelength but all these methods require addition of a chemical compound that has to be removed together with the products of reaction. The exception here is riboflavin, which does not have to be removed as it is present physiologically in the human body together with its photoproducts (Table 1).

Despite the introduction of a photoproduct-removal step, trace amounts of photoproducts are still present in blood components and so the risk of adverse transfusion-related reactions exists [6]. Therefore attempts were undertaken to develop an inactivation method that would not require the addition of chemical compounds, but solely rely on specific irradiation wavelength [7].

The microbiocidal and virucidal properties of UV irradiation have long been known. Moreover short-wave UVC-light (wavelength range 200-280 $\mathrm{nm}$ ) has already been in use for pathogen inactivation in serum, plasma as well as in blood products such as albumin, intravenous immunoglobulins and factor VIII concentrates [8].

\section{Therflex UV-Platelets System}

Therflex UV-Platelets System is the effect of a joint project between the German Red Cross

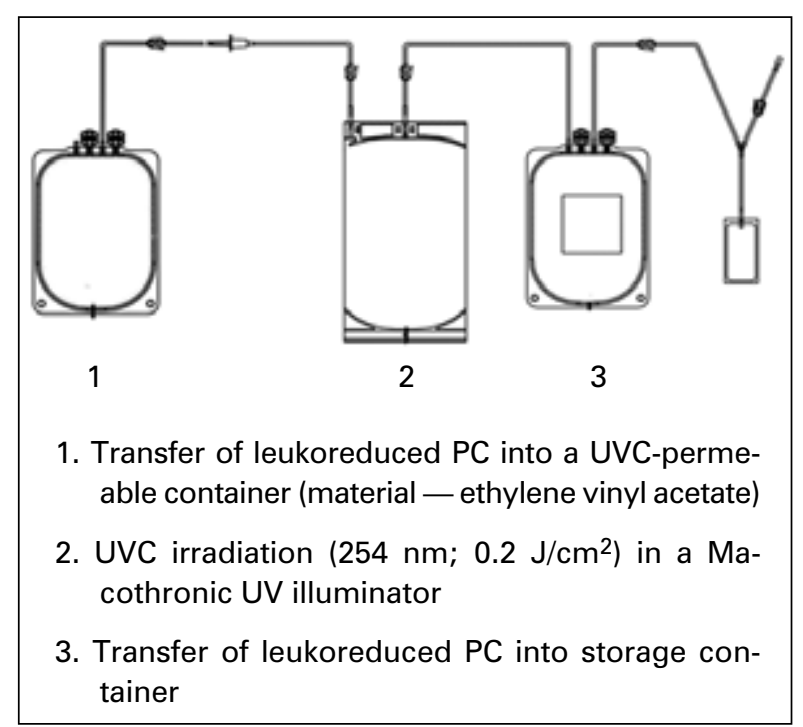

Figure 1. PC Pathogen inactivation with Theraflex UV Platelets system (courtesy of Macopharma)

and Macopharma. The technique relies solely on UVC irradiation and therefore recipients of PCs inactivated in this system are not exposed even to trace amounts of a chemical compound. The efficacy of UV irradiation in this system depends on both the wavelength and exposure time as well as on permeability of bags in which PCs are exposed to irradiation.

The process of $\mathrm{PCs}$ pathogen inactivation with the Theraflex UV-Platelets system is presented in Figure 1.

Theraflex UV-Platelets system is CE marked since 2009, but is not yet available for routine use [9].

Theraflex UV-Platelets system does not rely on photosensitive compounds but solely on irradiation (wavelength $254 \mathrm{~nm}$ ) that is not absorbed 
Table 2. Efficacy of UVC-based inactivation method

\begin{tabular}{|c|c|c|c|}
\hline Bacteria & $\begin{array}{l}\text { Degree of } \\
\text { reduction }(\log 10)\end{array}$ & Virus & $\begin{array}{l}\text { Degree of } \\
\text { reduction }(\log 10)\end{array}$ \\
\hline Escherichia coli & $\geq 4.4$ & HIV-1 & 1 \\
\hline Staphylococcus epidermidis & $\geq 4.8$ & Duck hepatitis B virus & $\geq 2.8$ \\
\hline Staphylococcus aureus & $\geq 4.8$ & $\mathrm{HCV}$ & $\geq 5.0$ \\
\hline Klebsiella pneumoniae & $>4.8$ & H5N1 & $\geq 5.1$ \\
\hline Pseudomonas aeruginosa & $>4.5$ & PRV & $2-3$ \\
\hline C.perfringens & $\geq 4.7$ & $\begin{array}{l}\text { Sindbis virus } \\
\text { (model for HCV) }\end{array}$ & $\geq 5.3$ \\
\hline Enterobacter cloacae & $\geq 4.3$ & PPV (model for parvo B19) & 5.0 \\
\hline Propionibacterium acnes & 4.5 & HSV & $\geq 2.8$ \\
\hline Protozoa & $\begin{array}{l}\text { Degree of reduction } \\
(\log 10)\end{array}$ & WNV & $3.5-4.0$ \\
\hline Trypanosoma cruzi & $>6$ & EMCV & $4.0-5.0$ \\
\hline Leishmania infantum & $>6.0$ & VSV & $\geq 6.3$ \\
\hline Babesia divergens & $>6$ & Parvo B19 & $\geq 4.0$ \\
\hline Plasmodium falciparum & $\geq 4.9$ & & \\
\hline
\end{tabular}

by proteins therefore conventional toxicity tests are not required. It should however be kept in mind that tolerability and immunogenicity of UVC-irradiated PCs need to be evaluated. Pohler et al. performed such studies on an animal model. Dogs were repeatedly transfused with autologous ultraviolet $\mathrm{C}$-inactivated platelets and no signs of intolerance or markers of immunological activation were reported $[10,11]$.

\section{Principle of the UVC-light method}

Theraflex UV-Platelets system uses UVC irradiation which is directly absorbed by nucleic acids of pathogens and leukocytes to form cyclobutane pyrimidine (1,3-diazine) and pyrimidine-pyrimidone dimmer, chemical compounds that ultimately prevent DNA polymerase from proceeding during transcription. Inactivation is effective when UVC light penetrates all PC layers. It has been proven that optimal UVC absorption is possible only under controlled, orbital agitation which is essential to ensure that blood products are homogeneously exposed to light. The latest version of Theraflex UV-Platelets system uses the dose of $0.2 \mathrm{~J} / \mathrm{cm}^{2}$ ) [12].

\section{Efficacy of UVC-light}

Evaluation studies on the efficacy of Therflex UV-Platelets system confirmed the reduction of clinically significant $\mathrm{G}(+)$ and $\mathrm{G}(-)$ bacteria (log reduction $>4.0)[10,13]$.
UVC irradiation contributes to virus inactivation in various degrees. Efficacy has been confirmed for vesicular stomatitis virus (VSV), Sindbis virus and hepatitis C virus (HCV). It is less effective for infectious agents such as pseudorabies virus (PRV) and West Nile virus (WNV). Although the UVC-based method has not been found effective against human immunodeficiency virus (HIV), it has not been deferred from further research because, unlike other photochemical or photodynamic inactivation techniques, the Theraflex UV-Platelets system inactivates small, non-enveloped DNA/RNA viruses like porcine parvovirus (PPV) (log reduction $4-5 \log )[10,12]$.

Pilot studies have demonstrated the UVC-based system effectively inactivates intraerythrocytic parasite - Babesia divergens (log reduction $>6.0$ ) [14]. Table 2 presents degrees of reduction for clinically significant bacteria, viruses and protozoa.

The Theraflex UV-Platelets system is also effective for leukocyte inactivation. It has been confirmed that even half the routine dose of energy $\left(0.1 \mathrm{~J} / \mathrm{cm}^{2}\right)$ completely inhibits the proliferative capacity of mononuclear cells in mixed lymphocyte culture (MLC). It can therefore be assumed that UVC irradiation prevents proliferation of T lymphocytes responsible for Transfusion Associated Graft versus Host Disease (TA-GvHD).

In vitro study results were confirmed in vivo on a xenogeneic transplantation mouse model. No human lymphocytes were found when mice were transfused UVC-irradiated human lymphocytes 
[15-17]. UVC at a dose of $0.1 \mathrm{~J} / \mathrm{cm}^{2}$ is sufficient to protect antigen presenting cells against stimulation with allogeneic cells, therefore most likely the method is also effective against antigen alloimmunization.

It has been found that a $0.1 \mathrm{~J} / \mathrm{cm}^{2}$ dose of UVC irradiation (half the routine dose) results in significant reduction of IL- $1 \beta$ and IL- 6 cytokine concentration in PCs as well as inhibition of IL-8 synthesis. IL-8 secreted during storage is a cytokine that significantly reduces the risk of Febrile Non Hemolytic Transfusion Reaction (FNHTR). However, it should be kept in mind that although UVC irradiation reduces or inhibits the synthesis of leukocyte-derived cytokines, it can enhance secretion of platelet-derived chemokines such as CCL5 (RANTES).

Assessment of white cell viability is based on assessment of cell integrity, apoptosis markers and proliferative capacity. Pohler et al. reported damage of leukocyte cell membrane on $3^{\text {rd }}$ storage day of PCs exposed to both gamma irradiation and UVC irradiation. On $7^{\text {th }}$ storage day, the leukocyte cell membrane in UVC-irradiated PCs was completely damaged while in the control PCs and gamma-irradiated PCs only in $20 \%$. The differences in the damage of leukocyte cell membranes were dependent on the UVC irradiation dose. This may suggest that the safe effect might be observed at lower doses [14, 18-20].

\section{Quality of Theraflex UV-irradiated PCs; clinical trials}

UVC irradiation not only damages nucleic acids of infectious agents and leukocytes, but affects the functional properties of platelets and plasma proteins. UVC irradiation was found to interrupt $\mathrm{S}-\mathrm{S}$ bridges in glycoprotein GPIIb/IIIa, a receptor protein of the integrin family involved in platelet adhesion and aggregation. Literature reports on the quality assessment of UVC-irradiated PCs are scarce. Studies on UVC-irradiated PCs performed by the German Red Cross report slightly increased metabolic activity (higher glucose consumption and higher lactate accumulation) and low activation (higher CD 62 antigen expression) as compared to control PCs.

In his studies Bashir et al confirmed higher metabolic activity but no differences in the degree of activation. During 7 days of storage CD 62P antigen expression and the amount of microparticles were at the same level. GP IIb/IIIa activation following UVC irradiation is caused by the decrease of disulfide bonds that regulate the integrin conformation system. The studies confirmed merely a moderate increase in free thiol groups due to the disruption of sulfide bonds in GP IIb/IIIa as a result of UVC irradiation.

The Therflex UV Platelets system is currently under clinical evaluation The first phase of clinical trials showed that UVC irradiated PCs were well tolerated by recipients.

No antibody formation against irradiated PCs was observed. Lower platelet recovery and shorter survival time in recipient's body were demonstrated $[21,22]$.

\section{Summary}

Like all other pathogen inactivation methods, the UVC technique has its advantages and limitations.

The advantage is undoubtedly the absence of photosensitizing compound and so the recipient of inactivated PCs is not exposed to even a trace of chemical compound. Clinically relevant $\mathrm{G}(+)$ and $\mathrm{G}(-)$ bacteria and small non-enveloped viruses are effectively inactivated. Additionally, it minimizes the risk of transmission of protozoa such as Trypanosoma cruzi and Leishmania infantum and effectively inactivates Babesia divergens. The UVC method is effective for leukocyte inactivation including T-cells responsible for TA-GvHD. Therefore, when patients at risk of developing TA-GvHD need $\mathrm{PC}$ transfusions, UVC irradiation is sufficient and there is no need for additional irradiation (with radiators). Moreover, pilot studies indicate that UVC irradiation not only inhibits cytokine synthesis, but also protects recipients against antigen alloimmunization. There are however limitations, such as: low efficacy against HIV (only 1 log reduction) and increased secretion of platelet chemokines.

\section{References}

1. Hellstern P, Sachse H, Schwinn H, et al. Manufacture and in vitro characterization of a solvent/detergent-treated human plasma. Vox Sang. 1992; 63(3): 178-185, doi: 10.1111/j.1423-0410.1992. tb05097.x, indexed in Pubmed: 1448962.

2. Mohr H, Lambrecht B, Selz A. Photodynamic virus inactivation of blood components. Immunol Invest. 1995; 24(1-2): 73-85, indexed in Pubmed: 7713607.

3. Prowse CV. Component pathogen inactivation: a critical review. Vox Sang. 2013; 104(3): 183-199, doi: 10.1111/j.1423-0410.2012.01662.x, indexed in Pubmed: 23134556.

4. Schlenke P. Pathogen inactivation technologies for cellular blood components: an update. Transfus Med Hemother. 2014; 41(4): 309-325, doi: 10.1159/000365646, indexed in Pubmed: 25254027. 
5. Heiden M, Seitz R. Pathogen inactivation - regulators aspects. ISBT Science Series. 2010; 5(n1): 279-281, doi: 10.1111/j.1751-2824.2010.01382.x.

6. Nubret K, Delhoume M, Orsel I, et al. Anaphylactic shock to fresh-frozen plasma inactivated with methylene blue. Transfusion. 2011; 51(1): 125-128, doi: 10.1111/j.1537-2995.2010.02800.x, indexed in Pubmed: 20667044.

7. Hart H, Reid K, Hart W. Inactivation of viruses during ultraviolet light treatment of human intravenous immunoglobulin and albumin. Vox Sang. 1993; 64(2): 82-88, doi: 10.1111/j.14230410.1993.tb02523.x, indexed in Pubmed: 8384394.

8. Seghatchian J, Tolksdorf F. Characteristics of the THERAFLEX UV-Platelets pathogen inactivation system - an update. Transfus Apher Sci. 2012; 46(2): 221-229, doi: 10.1016/j.transci.2012.01.008, indexed in Pubmed: 22365926.

9. Seltsam A, Müller TH. UVC Irradiation for Pathogen Reduction of Platelet Concentrates and Plasma. Transfus Med Hemother. 2011; 38(1): 43-54, doi: 10.1159/000323845, indexed in Pubmed: 21779205

10. Pohler P, Lehmann J, Veneruso V, et al. Evaluation of the tolerability and immunogenicity of ultraviolet $\mathrm{C}$-irradiated autologous platelets in a dog model. Transfusion. 2012; 52(11): 2414-2426, doi: 10.1111/j.1537-2995.2012.03583.x, indexed in Pubmed: 22404822.

11. Mohr H, Steil L, Gravemann U, et al. A novel approach to pathogen reduction in platelet concentrates using short-wave ultraviolet light. Transfusion. 2009; 49(12): 2612-2624, doi: 10.1111/j.1537-2995.2009.02334.x, indexed in Pubmed: 19682340.

12. Walther-Wenke G, Doerner R, Montag Th, et al. Working party on Bacteria Safety in Transfusion Medicine of the Advisory Board of the German Ministry of Health (Arbeitskreis Blut), Berlin, Germany. Bacterial contamination of platelet concentrates prepared by different methods: results of standardized sterility testing in Germany. Vox Sang. 2006; 90(3): 177-182, doi: 10.1111/j.1423-0410.2006.00753.x, indexed in Pubmed: 16507017.

13. Castro E, González LM, Rubio JM, et al. The efficacy of the ultraviolet $\mathrm{C}$ pathogen inactivation system in the reduction of $\mathrm{Ba}$ besia divergens in pooled buffy coat platelets. Transfusion. 2014; 54(9): 2207-2216, doi: 10.1111/trf.12598, indexed in Pubmed: 24666393
14. Pohler P, Müller M, Winkler C, et al. Pathogen reduction by ultraviolet C light effectively inactivates human white blood cells in platelet products. Transfusion. 2015; 55(2): 337-347, doi: 10.1111/trf.12836, indexed in Pubmed: 25134439.

15. Gravemann U, Pohler P, Lambrecht B, et al. Inactivation of peripheral blood mononuclear cells by UVC light using the Theraflex UV-Platelet system. Transfus Med Hemother. 2008; 35(suppl1): 4.

16. Jackman RP, Heitman JW, Marschner S, et al. Understanding loss of donor white blood cell immunogenicity after pathogen reduction: mechanisms of action in ultraviolet illumination and riboflavin treatment. Transfusion. 2009; 49(12): 2686-2699, doi: 10.1111/j.1537-2995.2009.02333.x, indexed in Pubmed: 19682337.

17. Heddle NM, Klama L, Singer J, et al. The role of the plasma from platelet concentrates in transfusion reactions. N Engl J Med. 1994; 331(10): 625-628, doi: 10.1056/NEJM199409083311001, indexed in Pubmed: 8052271.

18. Apelseth TO, Hervig TA, Wentzel-Larsen T, et al. Cytokine accumulation in photochemically treated and gamma-irradiated platelet concentrates during storage. Transfusion. 2006; 46(5): 800-810, doi: 10.1111/j.1537-2995.2006.00800.x, indexed in Pubmed: 16686848.

19. Verhaar R, Dekkers D, Cuyper IMDe, et al. UV-C irradiation disrupts platelet surface disulfide bonds and activates the platelet integrin IIb 3. Blood. 2008; 112(13): 4935-4939, doi: 10.1182/ blood-2008-04-151043.

20. Kannan M, Mohan KV, Kulkarni S, et al. Membrane array-based differential profiling of platelets during storage for 52 miRNAs associated with apoptosis. Transfusion. 2009; 49(7): 1443-1450, doi: 10.1111/j.1537-2995.2009.02140.x, indexed in Pubmed: 19389023.

21. Bashir S, Cookson P, Wiltshire M, et al. Pathogen inactivation of platelets using ultraviolet $\mathrm{C}$ light: effect on in vitro function and recovery and survival of platelets. Transfusion. 2013; 53(5): 990-1000, doi: 10.1111/j.1537-2995.2012.03854.x, indexed in Pubmed: 22905813.

22. Thiele T, Pohler P, Kohlmann T, et al. Tolerance of platelet concentrates treated with UVC-light only for pathogen reduction-a phase I clinical trial. Vox Sang. 2015; 109(1): 44-51, doi: 10.1111/ vox.12247, indexed in Pubmed: 25754418. 